\title{
LAPAROSCOPIC AND OPEN COLORECTAL SURGERY IN EVERYDAY PRACTICE: RETROSPECTIVE STUDY
}

\author{
Peter Wahl, $* \ddagger$ Dieter Hahnloser, $* \dagger$ Christian Chanson* AND Jean-Claude Givel $\$$ \\ * Cantonal Hospital, General Surgery, Fribourg, †University Hospital, Visceral and Transplantation Surgery, Zürich \\ and $\ddagger$ University of Lausanne Medical Centre, Visceral and Transplantation Surgery, Lausanne, Switzerland
}

\begin{abstract}
Background: Most studies available on laparoscopic colorectal surgery focus on highly selected patient groups. The aim of the present study was to review short- and long-term outcome of everyday patients treated in a general surgery department.

Methods: Retrospective review was carried out of a prospective database of all consecutive patients having undergone primary laparoscopic (LAP) or open colorectal surgery between March 1993 and December 1997. Follow-up data were completed via questionnaire.

Results: A total of 187 patients underwent LAP resection and 215 patients underwent open surgery. Follow up was complete in 95\% with a median of 59 months (range, 1-107 months) and 53 months (range, 1-104 months), respectively. There were 28 conversions $(15 \%)$ in the LAP group and these remained in the LAP group in an intention-to-treat analysis. The LAP operations lasted significantly longer for all types of resections $(205 \mathrm{vs} 150 \mathrm{~min}, P<0.001)$ and hospital stay was shorter $(8$ vs 13 days, $P<0.001)$. Recovery of intestinal function was faster in the LAP group, but only after left-sided procedures $(3$ vs 4 days, $P<0.01)$. However, preoperative patient selection (more emergency operations and patients with higher American Society of Anesthesiologists (ASA) score in the open group) had a major influence on these elements and favours the LAP group. Surprisingly, the overall surgical complication rate (including long-term complications such as wound hernia) was $20 \%$ in both groups with rates of individual complications also being comparable in both groups.

Conclusion: Despite a patient selection favourable to the laparoscopy group, only little advantage in postoperative outcome could be shown for the minimally invasive over the open approach in the everyday patient.
\end{abstract}

Key words: colorectal surgery, complications, laparoscopy, morbidity, mortality.

Abbreviations: ASA, American Society of Anesthesiologists; BMI, body mass index; LAP, laparoscopy.

\section{INTRODUCTION}

Since the first laparoscopic cholecystectomy in $1987,{ }^{1}$ minimally invasive techniques have been quickly adapted to a wide array of different operations including colorectal surgery. ${ }^{2}$ While some of the postulated advantages of laparoscopic (LAP) colorectal resection compared to open operation, such as earlier oral food intake, have been refuted by randomized trials, ${ }^{3}$ it has been shown, even if not as clearly as expected, that the overall postoperative recovery is faster after laparoscopy. ${ }^{4-7}$ Whether the consequent reduction in secondary costs outbalances the increased costs of longer operative times and higher material expenses still remains to be proven. ${ }^{8}$ The widespread adoption of laparoscopy in colorectal surgery has also been held up by various other factors.

Laparoscopic colorectal surgery is challenging even for experienced operators. ${ }^{9,10}$ Dissection is required in more than one quadrant and does not concern a fixed organ. Definitive conclusions are not yet available from the large prospective randomized trials started in the 1990s comparing open to laparoscopic resection in cancer patients. ${ }^{11-16}$ The first intermediate results have been FACS.

P. Wahl MD; D. Hahnloser MD; C. Chanson MD; J.-C. Givel MD, FRCS,

Correspondence: Professor Jean-Claude Givel, Department of Visceral and Transplantation Surgery CHUV, 1011 Lausanne, Switzerland.

Email: jean-claude.givel@chuv.hospvd.ch

Accepted for publication 1 April 2005. recently published. In the Clinical Outcomes of Surgical Therapy study the rates of cancer recurrence at 3 years were similar after laparoscopically assisted colectomy and open colectomy, suggesting that the laparoscopic approach is an acceptable alternative to open surgery for colon cancer. ${ }^{11}$

However, data available in the literature mostly concern highly selected patient groups, and there are few to no data on the use of laparoscopic colorectal resection in everyday practice. Laparoscopic colorectal surgery has been practised at the Cantonal Hospital in Fribourg since March 1993 for various indications and degrees of emergency. The aim of the present study was to document daily practice of laparoscopic colorectal surgery within a general surgery department, and to analyse complications and long-term outcomes.

\section{METHODS}

\section{Population and data collection}

The Cantonal Hospital in Fribourg, Switzerland, is the referral hospital for a population of approximately 230000 inhabitants. All patients requiring colorectal surgery between March 1993 and December 1997 were included in the present study to allow a possible, minimal follow up of 5 years. To reflect everyday practice, there were no exclusion criteria concerning age, comorbidity or type of disease. Emergencies were also included. Only patients with previous colorectal surgery were excluded. 
Data concerning patient demographics, nature of operation, inhospital progress and, wherever possible, complications and rehospitalizations, were gathered by chart review. All general practitioners, gastroenterologists and other hospitals involved in the follow-up care were contacted by questionnaire, in order to enable completion of the data concerning long-term outcomes. When necessary, patients were contacted directly by telephone. Data concerning long-term survival in cancer patients is subject to another ongoing study.

\section{Operative approach}

Patients were grouped according to the operative technique, laparoscopy (LAP) or laparotomy (open), used for the initial operation. To respect the intention-to-treat principle, all conversions from laparoscopy to laparotomy were included in the LAP group. The operative technique used for laparoscopy was standardized, and has been described previously. 17 The operative method was a free choice of the patient and the surgeon, but then followed the guidelines applied in the Cantonal Hospital of Fribourg. Laparoscopic colorectal surgery is regarded as an advanced technique to be carried out only by surgeons experienced in both conventional colorectal surgery and laparoscopy. Laparotomy was preferred in cases of obstruction or acute inflammatory pathology. Laparoscopy was offered principally to all patients needing a resection for polyps. Cancer patients were offered open resections, except selected cases of stage I cancers and only after thorough discussion of the potential risk associated with the technique, and some cases of stage IV cancers in elderly patients where the expected advantages of laparoscopy prevailed. Logistic restrictions relating to on-duty time often limited the availability of laparoscopy.

\section{Definitions}

Operations were defined as emergency if patients were admitted as emergencies and operated on within $48 \mathrm{~h}$; semi-elective if patients were admitted as emergencies but were operated on beyond $48 \mathrm{~h}$ following appropriate medical treatment; and as elective if the patients were admitted on a planned basis. Conversion was defined strictly. Operations where a brief laparoscopic exploration was performed before laparotomy were also considered as conversions. Conversion due to adherence, inflammation or anatomical difficulties were grouped as inaccessible to laparoscopy as evaluated by the operator. Complications were classified as early when diagnosed within 30 postoperative days and as late if diagnosed after 30 days. Operative mortality was defined conventionally as occurring within 30 days after the operation.

\section{Statistical analysis}

Statistical analysis was done using the $t$-test, Wilcoxon/KruskalWallis tests, Pearson test, or $\chi^{2}$ test, depending on the data characteristics. Statistical significance was accepted at $P \leq 0.05$. $P>0.1$ was marked as non-significant to simplify reading of the tables.

\section{RESULTS}

\section{Patient data and operations}

A total of 451 patients fulfilled the inclusion criteria. Because during the study period some operations were performed only by laparotomy and thus no comparison with laparoscopy was possible, 46 patients (five colostomies, 16 atypical or segmental transverse resections, 11 Hartmann procedures, six combined left and right resections and eight subtotal or total colectomies) were excluded. Three more patients had to be excluded because of missing data. Finally, 402 patients were included, 187 in the LAP group and 215 in the open group.

Patient demographics, indications for surgery, and types of procedures are shown in Table 1. Gender, age and body mass index (BMI) did not differ significantly between both groups. The distribution of American Society of Anesthesiologists (ASA) scores was similar in patients undergoing elective operation. Reflecting the larger proportion of emergencies, the open group had a significantly higher global ASA score $(P<0.001)$. The ASA score also correlated with increasing age $(P<0.001)$ but not with gender nor with the BMI. It is not surprising that the distribution of pathology and emergency surgery is unequal between both groups, mainly due to the aforementioned restrictions concerning the availability of laparoscopy.

Except for the small number of cases of sutures without resection in case of perforation, and with the exception of ileocaecal resections, laparoscopic operations always lasted significantly longer than the same procedure performed by laparotomy (Table 2).

\section{Conversion}

Twenty-eight laparoscopies were converted to open surgery (conversion rate of $15 \%$, Table 3 ). The most common reason for conversion was inaccessibility to laparoscopy as evaluated by the operator (17 cases, $61 \%$ of conversions), followed by four cases $(14 \%)$ of unsatisfactory anastomosis (one malrotation, two uncontrollable leakages at peranal air test and one stapler misfiring). Four other patients $(14 \%)$ were converted for iatrogenic lesions, such as uncontrollable bleeding (two cases, 7\%), accidental enterotomy (one case, $4 \%$ ) or ureteric lesions (one case, $4 \%$ ). However, two additional accidental enterotomies, two vascular and one ureteric lesions could be managed laparoscopically and conversion was not necessary. Thus, accidental digestive, vascular or ureteric lesions accounted for nine intraoperative complications at laparoscopy $(4.8 \%)$. In two cases $(7 \%)$ in our early experience, conversion was necessary because the polyp could not be found. Malfunction of the endoscopic coagulation led to another one conversion, also in our early experience. Overall, conversion was more frequent among patients with higher ASA score and among emergencies. Age, gender, BMI and the pathology had no significant influence on conversion. Conversion patients had a longer postoperative recovery although the operation did not last longer compared to the laparoscopic cases.

\section{In-hospital evolution}

Recovery of intestinal function, evaluated by the number of postoperative days to the first bowel movement, is indicated in Table 4. A significantly faster recovery could be seen following laparoscopy, but only for left-sided procedures. The hospital stay was significantly shorter in the LAP group for nearly all types of 
Table 1. Demographic data

\begin{tabular}{|c|c|c|c|}
\hline & $\begin{array}{l}\text { Open } \\
n(\%)\end{array}$ & $\begin{array}{c}\text { LAP } \\
n(\%)\end{array}$ & $P$ \\
\hline$n(\%)$ & $215(53)$ & $187(47)$ & \\
\hline Male : female $(\%: \%)$ & $114: 101(53: 47)$ & $99: 88(53: 47)$ & NS \\
\hline Age, median (range) & $68.8(17.4-92.4)$ & $67.0(17.7-86.0)$ & NS \\
\hline BMI, median (range) $\dagger$ & $23.9(13.7-39.5)$ & $24.4(16.2-40.3)$ & NS \\
\hline \multicolumn{4}{|l|}{ ASA, $n$ (\% of group) $\ddagger$} \\
\hline I-II & $109(52)$ & $152(81)$ & $<0.001$ \\
\hline III-IV§ & $102(48)$ & 35 (19) & $<0.001$ \\
\hline \multicolumn{4}{|l|}{ Degree of emergency } \\
\hline Emergency & $76(35)$ & $12(6)$ & $<0.001$ \\
\hline Semi-elective & $19(9)$ & $14(7)$ & NS \\
\hline Elective & $120(56)$ & $161(86)$ & $<0.001$ \\
\hline \multicolumn{4}{|l|}{ Indications for surgery } \\
\hline Colorectal cancer & $119(55)$ & $71(40)$ & 0.001 \\
\hline Diverticular disease & $56(26)$ & $85(46)$ & $<0.001$ \\
\hline Colorectal adenoma & $6(3)$ & $20(11)$ & 0.004 \\
\hline Perforation & $9(4)$ & $3(2)$ & NS \\
\hline Ischaemia & $7(3)$ & $2(1)$ & NS \\
\hline Volvulus & $6(3)$ & $1(1)$ & NS \\
\hline Inflammatory bowel disease & $5(2)$ & $1(1)$ & NS \\
\hline Other cancer 9 & $3(1)$ & $1(1)$ & NS \\
\hline Dolichocolon" & - & $4(2)$ & NS \\
\hline Appendicitis & $1(1)$ & $2(1)$ & NS \\
\hline Lower gastrointestinal bleeding & $2(1)$ & - & NS \\
\hline Other diagnosis $\dagger \dagger$ & $2(1)$ & - & NS \\
\hline \multicolumn{4}{|l|}{ Types of procedures } \\
\hline Suture & $4(2)$ & $3(2)$ & NS \\
\hline Ileo-caecal resection & $6(3)$ & $4(2)$ & NS \\
\hline Right hemicolectomy & $56(26)$ & $13(7)$ & $<0.001$ \\
\hline Left hemicolectomy & $32(15)$ & $9(5)$ & $<0.001$ \\
\hline Sigmoidectomy & $66(31)$ & $113(60)$ & $<0.001$ \\
\hline Low anterior resection & $43(20)$ & $35(19)$ & NS \\
\hline Abdominoperineal resection & $8(4)$ & $10(5)$ & NS \\
\hline
\end{tabular}

ASA, American Society of Anesthesiologists; BMI, body mass index; LAP, laparoscopy; open, laparotomy; NS, not significant.

$\dagger$ Available for $n=132(61 \%)$ in laparotomy and $n=160(86 \%)$ in laparoscopy; †available for $n=211(98 \%)$ in laparotomy and all in laparoscopy; §included one case with ASA V operated by laparotomy; $\uparrow$ two gynaecological cancers, one histiocytoma, one peritoneal carcinomatosis from breast cancer; $\dagger \dagger$ one amyloidosis, one stenosis after radiotherapy.

Table 2. Operative time

\begin{tabular}{|c|c|c|c|}
\hline Operative time (min) median (10-90\%) & Open & LAP & $P$ \\
\hline Suture $(4 / 3)$ & $128(50-145)$ & $110(95-160)$ & NS \\
\hline Right hemicolectomy (55/15) & $130(90-200)$ & $210(156-252)$ & $<0.001$ \\
\hline Left hemicolectomy $(32 / 9)$ & $163(111-220)$ & $215(175-279)$ & 0.003 \\
\hline Sigmoidectomy $(65 / 113)$ & $150(103-207)$ & $180(135-270)$ & $<0.001$ \\
\hline
\end{tabular}

LAP, laparoscopy; NS, not significant; open, laparotomy.

$\dagger$ Data missing for two laparotomy cases.

䡮 laparotomy/n laparoscopy.

procedures, with the exception of sutures, low anterior resections and the laparoscopically assisted abdominoperineal resection.

\section{Complications}

Follow-up data could be gathered for 202 patients (94\%) in the open group and $179(96 \%)$ in the LAP group. Median follow up was 53 months (range, 1-104 months) and 59 months (range,
1-107 months), respectively. Surgical complications are listed in Table 5 .

A clear distinction between early and late complications, as defined in the previous section, could not be made simply on the nature of the event because septic complications, bowel obstruction and wound herniations were observed within the first 30 days as well as after 30 days. The overall surgical complication rate was not significantly different between open and LAP 
Table 3. Conversion cases

\begin{tabular}{|c|c|c|c|}
\hline & $\begin{array}{c}\text { Conversion } \\
n(\%)\end{array}$ & $\begin{array}{c}\text { LAP finished } \\
n(\%)\end{array}$ & $P$ \\
\hline \multicolumn{4}{|l|}{ Demographic data } \\
\hline$n(\%)$ & $28(15)$ & $159(85)$ & \\
\hline Male : female $(\%: \%)$ & $12: 16(43: 57)$ & $87: 72(55: 45)$ & NS \\
\hline Age, median (range) & $71.2(26.5-83.2)$ & $66.3(17.7-86.0)$ & NS \\
\hline BMI, median (range) $\dagger$ & $24.5(20.5-31.9)$ & $24.3(16.2-40.4)$ & NS \\
\hline \multicolumn{4}{|l|}{ ASA-score, $n$ ( $\%$ of group) } \\
\hline I-II & $19(68)$ & $133(84)$ & 0.048 \\
\hline III-IV & $9(32)$ & $26(16)$ & 0.048 \\
\hline \multicolumn{4}{|l|}{ Degree of emergency } \\
\hline Emergency & $5(18)$ & $7(4)$ & 0.007 \\
\hline Semi-elective & $7(25)$ & $7(4)$ & $<0.001$ \\
\hline Elective & $16(57)$ & $145(92)$ & $<0.001$ \\
\hline \multicolumn{4}{|l|}{ Indications for surgery } \\
\hline Colorectal cancer & $9(32)$ & $65(41)$ & NS \\
\hline Diverticular disease & $14(50)$ & $68(43)$ & NS \\
\hline Other diagnosis & $5(18)$ & $26(16)$ & NS \\
\hline \multicolumn{4}{|l|}{ Operative data } \\
\hline Operative time (min) median (10-90\%) & $188(122-378)$ & $205(140-285)$ & NS \\
\hline First bowel movement (days) median (10-90\%) & $4(2-5.5)$ & $3(2-5)$ & $<0.001$ \\
\hline Hospital stay (days) median (10-90\%) & $13(10-24)$ & $7(5-20)$ & 0.007 \\
\hline
\end{tabular}

ASA, American Society of Anesthesiologists; BMI, body mass index; LAP, laparoscopy; NS, not significant.

$\dagger$ Available for $n=19$ (68\%) conversion and $n=141$ (89\%) laparoscopy.

Table 4. Postoperative evolution

\begin{tabular}{|c|c|c|c|}
\hline & Open & LAP & $P$ \\
\hline \multicolumn{4}{|c|}{ First bowel movement (days) median (10-90) } \\
\hline Total $(202 / 180) \dagger+$ & $4(3-7)$ & $3(2-5)$ & $<0.001$ \\
\hline Suture $(4 / 3)$ & $4.5(3-6)$ & $3(3,4)$ & NS \\
\hline Ileocaecal resection $(6 / 4)$ & $4(3-5)$ & $3.5(2-4)$ & NS \\
\hline Right hemicolectomy (54/12) & $4(3-7)$ & $3.5(2-8)$ & NS \\
\hline Left hemicolectomy $(31 / 9)$ & $4(2-8)$ & $2(2-6)$ & 0.01 \\
\hline Sigmoidectomy $(60 / 111)$ & $5(3-7)$ & $3(1-5)$ & $<0.001$ \\
\hline Low anterior resection $(41 / 31)$ & $4(3-8)$ & $3(2-5)$ & $<0.001$ \\
\hline Abdominoperineal resection $(6 / 10)$ & $7.5(4-9)$ & $4(1-5)$ & 0.007 \\
\hline \multicolumn{4}{|l|}{ Hospital stay (days) median (10-90\%) } \\
\hline Total $(215 / 187) \ddagger$ & $13(9-36)$ & $8(5-22)$ & $<0.001$ \\
\hline Suture $(4 / 3)$ & $25(9-44)$ & $16(7-17)$ & NS \\
\hline Ileo-caecal resection $(6 / 4)$ & $11.5(9-16)$ & $7.5(6-9)$ & 0.04 \\
\hline Right hemicolectomy $(56 / 13)$ & $13(10-29)$ & $8(7-14)$ & 0.01 \\
\hline Left hemicolectomy $(32 / 9)$ & $13(9-27)$ & $7(5-11)$ & 0.003 \\
\hline Sigmoidectomy $(66 / 113)$ & $14(9-29)$ & $7(4-15)$ & $<0.001$ \\
\hline Low anterior resection $(43 / 35)$ & $13(9-38)$ & $8(5-29)$ & NS \\
\hline Abdominoperineal resection $(8 / 10)$ & $26.5(17-37)$ & $19.5(9-38)$ & NS \\
\hline
\end{tabular}

LAP, laparoscopy; NS, not significant; open, laparotomy.

$\dagger$ Data missing for 13 cases laparotomy and 7 cases laparoscopy.

$\ddagger n$ laparotomy/n laparoscopy.

( $20 \%$ vs $21 \%$, respectively, $P=0.86$ ) with early and late complications occurring in both groups with no significant difference.

Temporary paresis of the peroneal nerve affected three patients and occurred only in the LAP group after sigmoidectomies or low anterior resections, although the same stirrups were used and lateral padding was also identical to that for open surgery patients. No significant association with longer operative time was noted. Positioning of the patients on the operation table was given special attention and this problem did not occur again in our later experience.

Major long-term complications were bowel obstruction and anastomotic strictures, comparable in both groups. No significant difference was observed in the rate of complications after conversion compared to operations finished by laparoscopy. Complications of the subgroup of conversions include one wound infection, one fistula, one wound hernia and one bowel obstruction.

The 30-day mortality rate was $7 \%$ (15 patients) in the open group and $1.1 \%$ (two patients) in the LAP group, all in-hospital $(P<0.001)$. Half of these patients were operated on as emergencies. Median age was over 74 years in both groups. Approximately half of these patients in both groups had an ASA score of III-IV. The cause of death was related to the diagnosis leading to the operation for one patient operated on by laparoscopy and 
Table 5. Postoperative surgical complications

\begin{tabular}{|c|c|c|c|c|}
\hline Complication & $\begin{array}{c}\text { Total early/late } \\
n(\%)\end{array}$ & $\begin{array}{l}\text { Open } \\
n(\%)\end{array}$ & $\begin{array}{l}\text { LAP } \\
n(\%)\end{array}$ & $P$ \\
\hline Anastomotic bleeding & $1 / 0(100 / 0)$ & - & $1(0.5)$ & NS \\
\hline Intra-abdominal haematoma & $2 / 0(100 / 0)$ & $1(0.5)$ & $1(0.5)$ & NS \\
\hline Anastomotic leakage & $14 / 0(100 / 0)$ & $6(3.0)$ & $8(4.6)$ & NS \\
\hline Intra-abdominal/retroperitoneal abscess & $2 / 3(40 / 60)$ & $4(1.8)$ & $1(0.5)$ & NS \\
\hline Wound infection & $23 / 1(96 / 4)$ & $17(7.9)$ & $7(3.7)$ & 0.06 \\
\hline Fistula & $5 / 4(56 / 44)$ & $6(2.8)$ & $3(1.6)$ & NS \\
\hline Severe sepsis/septic shock & $5 / 1(83 / 17)$ & $4(1.9)$ & $2(1.1)$ & NS \\
\hline Anastomotic stricture & $2 / 9(18 / 82)$ & $3(1.5)$ & $8(4.6)$ & 0.08 \\
\hline Bowel obstruction & $5 / 15(25 / 75)$ & $11(5.1)$ & $10(5.3)$ & NS \\
\hline Wound hernia & $2 / 14(13 / 87)$ & $9(4.2)$ & $7(3.7)$ & NS \\
\hline Peroneal neuropathy & $3 / 0(100 / 0)$ & - & 3 (1.6) & 0.09 \\
\hline Total, $n$ (\% of group) & $64 / 47(58 / 42)$ & $43(20)$ & $40(21)$ & NS \\
\hline 30-day mortality, $n(\%)$ & & $15(7.0)$ & $2(1.1)$ & $<0.001$ \\
\hline
\end{tabular}

LAP, laparoscopy; NS, not significant; open, laparotomy.

Table 6. Comparison of selected postoperative surgical complications

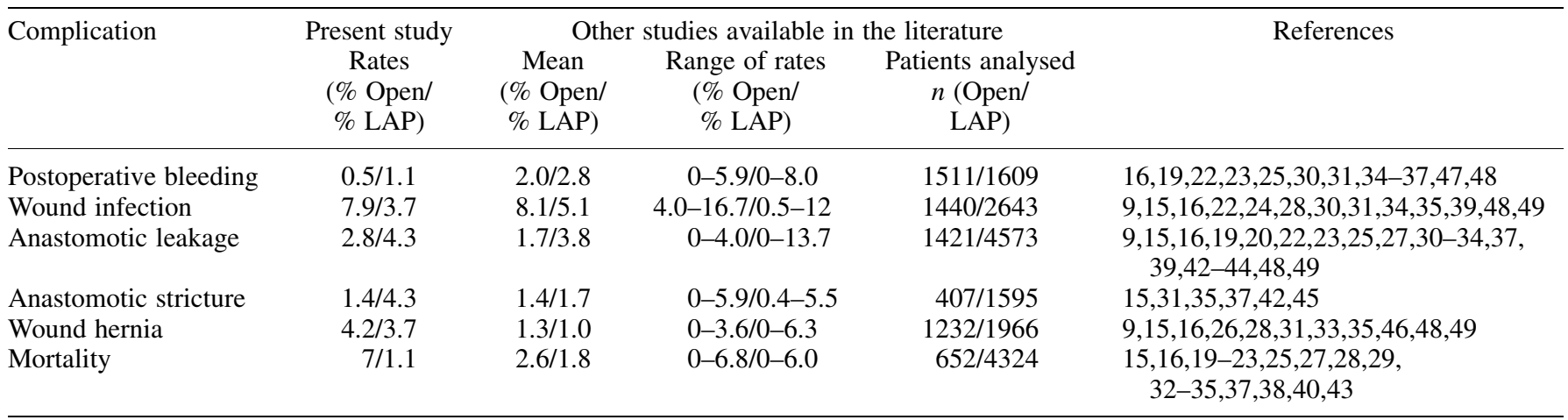

LAP, laparoscopy; open, laparotomy.

for six patients in the open group (all due to sepsis secondary to diverticulitis).

\section{DISCUSSION}

Following the excellent results of laparoscopic cholecystectomy, laparoscopy has been applied to a wide range of abdominal operations. ${ }^{2}$ However, it is still not clear whether advantages such as faster recovery and shorter hospital stays ${ }^{18}$ outweigh possible disadvantages such as prolonged operative time, increased technical difficulties and uncertain long-term outcome in cancer patients. Despite all this and the fact that most available evidence comes from specialized centres and series of highly selected patients, laparoscopic colorectal surgery has found a widespread application. The present study compared morbidity, postoperative recovery and long-term complications of laparoscopic and open colorectal surgery as encountered every day in a general surgery department and found, despite a favourable patient selection, only little advantage of the minimal invasive approach.

Laparoscopic colorectal surgery has been performed at the Cantonal Hospital of Fribourg since its beginning. The present retrospective study documents the results of open and laparoscopic colorectal surgery in a patient population with mixed indications and various degrees of disease severity. A criticism of the present study might be that the study is retrospective, that the two groups are too different to compare and that laparoscopic cases were highly selected. This cannot be denied, but given that a high level of evidence is very difficult to obtain for the everyday patient mix, these data certainly contribute to better specify the indications of laparoscopic colorectal surgery. Furthermore, with a minimal follow up of 5 years, the present study gives an insight into long-term outcome.

Unlike large specialized tertiary hospitals, nearly half of the patients in the present study were admitted through the emergency department and needed emergency surgery. Those patients often present with septic or mechanical complications and time often limits preoperative investigations and preparation. Therefore, a laparoscopic approach was not always feasible. Another reason why most emergency operations were performed by an open approach is the fact that laparoscopic colorectal surgery demands advanced laparoscopic skills, and personnel with enough experience was not always available. This selection bias of more patients with advanced or complicated disease in the open group should theoretically favour the LAP group with regards to postoperative recovery. However, a significant faster return of intestinal function after laparoscopy was found only for left-sided resections and might well be explained by the unequal distribution of emergencies. These results are similar to the literature, with mean days to first bowel movement of 3-6 days (mean 5 days, 
total 530 patients) after laparotomy and 3-5 days (mean 4 days, total 1260 patients) after laparoscopy. ${ }^{19-26}$

Patients in the open group stayed on average 5 days longer than patients in the LAP group. This is not surprising because the proportion of severely ill patients was higher in the open group. In the Cantonal Hospital of Fribourg, postoperative feeding is not subject to strict guidelines but is left to the discretion of the treating physician, and hospital discharge often is delayed by nursing and social problems. Inter-institutional comparability of the length of hospital stay after colorectal surgery is limited because the patient mix analysed and the organization and availability of nursing care and convalescence institutions are greatly variable but have a major influence on patient discharge.16,18,25 This is well-illustrated by the great variability of the length of hospital stay found in the literature: mean hospital stay for open surgery ranged from 6 to 18 days after open surgery and from 4 to 14 days after laparoscopic resections, with a high dependency on the type of procedure. $15,16,19-24,26-42$

Laparoscopic colorectal resections lasted longer and were not without complications in the present study. Nearly all reports in the literature describe longer duration of operation for laparoscopic operations, ${ }^{15,16,19-24,26,28-30,32,34-42}$ but these values are difficult to compare because the operative time is highly dependent of the type of operation and decreases with experience gained by the surgeon. 16,20,28,32,33 Intraoperative complications, like accidental enterotomy, uncontrollable bleeding and ureteric lesions, occurred in $4.8 \%$ in the laparoscopy group in the present study, comparable to the mean rate of $5.2 \%$ found in the literature in laparoscopic operations (total 4886 patients). 10,15,19,22,23,25,28,42,43 One study dedicated to intraoperative complications during laparoscopy, and two small series show rates as high as 10-15\%.9,33,37 However, not all intraoperative complications require conversion. The overall conversion rate of $15 \%$ in the present study is comparable to most conversion rates reported in the literature, where rates range from $0 \%$ to $35 \%$ but are mainly between $10 \%$ and $20 \% .10,15,19-44$ Operation time required in the present study for conversion cases remained similar to that used for operations completed by laparoscopy, indicating that conversion was chosen early if the operation could not be performed by laparoscopy. Postoperatively, the behaviour of the conversion patients was similar to those who underwent open surgery. Thus, conversion did not imply a worse outcome and should not be regarded by itself as a complication.

In the present study the 30-day mortality rate was higher in the open surgery group compared to the LAP group $(P<0.01)$. This can be explained by the fact that $50 \%$ of patients dying within 30 days were emergency operations and more emergency operations were performed in the open group (35\% of all open) than in the laparoscopy group (6\% of all laparoscopy operations). Like in other studies, patients who died within 30 days after operation in the present study were significantly older $(P=0.003)$. A comparison of mortality and other complications between the present study and other studies available in the literature, is given in Table 6.

One of the most striking findings of the present study is that the overall rate of surgical complications was similar in both groups with approximately one out of five patients affected, despite the selection bias favourable to the LAP group (less emergency operations and patients with lower ASA score, two well-known risk factors for complication). This cannot be simply explained by the learning curve of laparoscopic resections (around 40 operations ${ }^{10}$ ), especially because complications were evenly distributed during the study period. Even grouping all the septic complica- tions (wound infections, anastomotic leakage, fistula, abscesses and severe sepsis/septic shock) did not produce a significant advantage for the minimal invasive group. Wound infections have been studied extensively in large series showing rates ranging from $3 \%$ to $10 \% 45,46,50-52$ after open surgery and $1.9 \%$ after laparoscopic resection. ${ }^{46}$ This is not surprising because in everyday practice patients presenting with acute septic complications at the time of surgery and therefore at higher risk of wound infection, in general, are operated on using an open approach. In the present study the wound infection rate of $7.9 \%$ after open surgery is twice as high as the $3.7 \%$ observed after laparoscopy, but the difference falls just short of significance $(P=0.06)$.

Another feared complication after colorectal surgery is anastomotic leakage, occurring in $0-6 \%$ after colon resections. ${ }^{47,53}$ Anastomotic leakage can be one long-term cause of strictures described in up to $20 \%$ after low anterior resection in a study systematically assessing the incidence of strictures. ${ }^{54}$ No significant difference in anastomotic leakage and stricture rates was expected nor observed in the present study. Simple sutures and abdominoperineal resections, where no anastomosis is performed, were excluded from this analysis.

One measurement of long-term outcome after colorectal surgery for benign disease is the occurrence of wound hernias and/or the need for rehospitalization or surgery for bowel obstructions due to adhesions. Theoretically, the smaller incisions used for laparoscopic surgery should lower the risk of wound hernia. Indeed, reports specifically directed to the incidence of wound hernia after abdominal surgery for various indications show generally lower rates after laparoscopy $(1.6 \%)$ than after laparotomy $(4.2-10 \%) .50,51,55,56$ In the present study the rates of wound hernias after laparoscopy were high (3.7\% compared to $4.2 \%$ after open surgery) and must be considered as a minimum in both groups because patients were not re-evaluated systematically for this complication. However, most cases of wound hernias after laparoscopy concerned either patients who had conversion or who had hernias at the site of the transverse minilaparotomy used to extract the resected segment.

\section{CONCLUSIONS}

As shown by several studies, the laparoscopic approach to a wide range of colorectal diseases is technically feasible and safe. For carefully selected patients, conversion and complication rates can be kept low. However, in the present study reflecting everyday practice, laparoscopic colorectal surgery had similar postoperative recovery, short- and long-term complication rates compared to open surgery, even though there was a favourable patient selection for the LAP group. This observation needs to be further investigated, especially for the every day patient even if this might suggest that the disadvantages of laparoscopy outweigh the advantages.

\section{ACKNOWLEDGEMENT}

We wish to thank Professor M. Clements, University of the West of England, Bristol, for her invaluable help with the statistical analysis.

\section{REFERENCES}

1. Dubois F, Icard P, Berthelot G, Levard H. Coelioscopic cholecystectomy: preliminary report of 36 cases. Ann. Surg. 1990; 211: $60-2$. 
2. Soper NJ, Brunt LM, Kerbl K. Laparoscopic general surgery. N. Engl. J. Med. 1994; 330: 409-19.

3. Lewis SJ, Egger M, Sylvester PA, Thomas S. Early enteral feeding versus 'nil by mouth' after gastrointestinal surgery: systematic review and meta-analysis of controlled trials. BMJ 2001; 323: $1-5$.

4. Stocchi L, Nelson H. Laparoscopic colectomy for colon cancer: trial update. J. Surg. Oncol. 1998; 68: 255-67.

5. Tomita H, Marcello PW, Milsom JW. Laparoscopic surgery of the colon and rectum. World J. Surg. 1999; 23: 397-405.

6. Maxwell-Armstrong CA, Robinson MH, Scholefield JH. Laparoscopic colorectal cancer surgery. Am. J. Surg. 2000; 179: 500-7.

7. Weeks J, Nelson H, Gelber S, Sargent D, Schroeder G. Shortterm quality-of-life outcomes following laparoscopic-assisted colectomy vs open colectomy for colon cancer. JAMA 2002; 287: 321-8.

8. Philipson BM, Bokey EL, Moore JW, Chapuis PH, Bagge E. Cost of open versus laparoscopically assisted right hemicolectomy for cancer. World J. Surg. 1997; 21: 214-17.

9. Agachan F, Joo JS, Weiss EG, Wexner SD. Intraoperative laparoscopic complications: are we getting better? Dis. Colon Rectum 1996; 39: S14-19.

10. Bennett CL, Stryker SJ, Ferreira MR, Adams J, Beart RW. The learning curve for laparoscopic colorectal surgery: preliminary results from a prospective analysis of 1194 laparoscopic-assisted colectomies. Arch. Surg. 1997; 132: 41-4.

11. Clinical Outcomes of Surgical Therapy Study Group. A comparison of laparoscopically assisted and open colectomy for colon cancer. N. Engl. J. Med. 2004; 350: 2050-9.

12. The COLOR Study Group. COLOR: a randomized clinical trial comparing laparoscopic and open resection for colon cancer. Dig. Surg. 2000; 17: 617-22.

13. Stead ML, Brown JM, Bosanquet $\mathrm{N}$ et al. Assessing the relative costs of standard open surgery and laparoscopic surgery in colorectal cancer in a randomised controlled trial in the United Kingdom. Crit. Rev. Oncol. Hematol. 2000; 33: 99-103.

14. Kockerling F, Schneider C, Reymond MA et al. Early results of a prospective multicenter study on 500 consecutive cases of laparoscopic colorectal surgery. Laparoscopic Colorectal Surgery Study Group (LCSSG). Surg. Endosc. 1998; 12: 37-41.

15. Regadas FS, Ramos JR, Souza JV et al. Laparoscopic colorectal procedures: a multicenter Brazilian experience. Surg. Laparosc. Endosc. Percutan. Tech. 1999; 9: 395-8.

16. Lacy AM, Garcia-Valdecasas JC, Delgado S et al. Laparoscopyassisted colectomy versus open colectomy for treatment of nonmetastatic colon cancer: a randomised trial. Lancet 2002; 359: 2224-9.

17. Petropoulos P. Update in laparoscopic surgery. Dig. Surg. 1997; 14: 444-9.

18. Guller U, Jain N, Hervey S, Purves H, Pietrobon R. Laparoscopic $v s$ open colectomy: outcomes comparison based on large nationwide databases. Arch. Surg. 2003; 138: 1179-86.

19. Ramos JM, Beart RW, Goes R, Ortega AE, Schlinkert RT. Role of laparoscopy in colorectal surgery: a prospective evaluation of 200 cases. Dis. Colon Rectum 1995; 38: 494-501.

20. Huscher C, Silecchia G, Croce E et al. Laparoscopic colorectal resection. A multicenter italian study. Surg. Endosc. 1996; 10: 875-9.

21. Milsom JW, Bohm B, Hammerhofer KA, Fazio V, Steiger E, Elson $\mathrm{P}$. A prospective randomized trial comparing laparoscopic versus conventional techniques in colorectal cancer surgery: a preliminary report. J. Am. Coll. Surg. 1998; 187: 46-57.

22. Schiedeck TH, Schwander O, Baca I et al. Laparoscopic surgery for the cure of colorectal cancer. Results of a German five-center study. Dis. Colon Rectum 2000; 43: 1-8.

23. Hong D, Tabet J, Anvari M. Laparoscopic vs open resection for colorectal adenocarcinoma. Dis. Colon Rectum 2001; 44: $10-19$.
24. Goh YC, Eu KW, Seow-Choen F. Early postoperative results of a prospective series of laparoscopic vs open anterior resections for rectosigmoid cancers. Dis. Colon Rectum 1997; 40: 776-80.

25. Scheidbach H, Schneider C, Baerlehner E, Konradt J, Koeckerling F. Laparoscopic anterior resection for rectal carcinoma. Laparosc. Endosc. Surg. Oncol. 2001; 10: 599-609.

26. Fleshmann JW, Wexner SD, Anvari M et al. Laparoscopic vs open abdominoperineal resection for cancer. Dis. Colon Rectum 1999; 42: 930-9.

27. Monson JRT, Darzi A, Carey PD, Guillou PJ. Prospective evaluation of laparoscopic-assisted colectomy in an unselected group of patients. Lancet 1992; 340: 831-3.

28. Hoffman GC, Baker JW, Fitchett CW, Vansant JH. Laparoscopicassisted colectomy. Initial experience. Ann. Surg. 1994; 219: 732-43.

29. Begos DG, Arsenault J, Ballantyne GH. Laparoscopic colon and rectal surgery at a VA hospital. Surg. Endosc. 1996; 10: $1050-6$

30. Bruce CJ, Coller JA, Murray JJ, Schoetz DJ, Roberts PL, Rusin LC. Laparoscopic resection for diverticular disease. Dis. Colon Rectum 1996; 39: S1-6.

31. Franklin ME, Rosenthal D, Abrego-Medina D et al. Prospective comparison of open $v s$ laparoscopic colon surgery for carcinoma. Dis. Colon Rectum 1996; 39: S35-46.

32. Gellman L, Salky B, Edye M. Laparoscopic assisted colectomy. Surg. Endosc. 1996; 10: 1041-4.

33. Lord SA, Larach SW, Ferrara A, Williamson PR, Lago CP, Lube MW. Laparoscopic resections for colorectal carcinoma. A three year experience. Dis. Colon Rectum 1996; 39: 148-54.

34. Bokey EL, Moore JW, Keating JP, Zelas P, Chapuis PH, Newland RC. Laparoscopic resection of the colon and rectum for cancer. Br. J. Surg. 1997; 84: 822-5.

35. Leung KL, Kwok SP, Lau WY et al. Laparoscopic-assisted resection of rectosigmoid carcinoma. Immediate and medium-term results. Arch. Surg. 1997; 132: 761-4.

36. Khalili TM, Fleshner PR, Hiatt JR et al. Colorectal cancer. A comparison of laparoscopic with open approaches. Dis. Colon Rectum 1998; 41: 832-8.

37. Molenaar $\mathrm{CBH}$, Bijnen $\mathrm{AB}$, de Ruiter P. Indications for laparoscopic colorectal surgery. Results from the Medical Centre Alkmaar. Surg. Endosc. 1998; 12: 42-5.

38. Psaila J, Bulley SH, Ewings P, Sheffield JP, Kennedy RH. Outcome following laparoscopic resection for colorectal cancer. $\mathrm{Br}$. J. Surg. 1998; 85: 662-4.

39. Leung KL, Meng WC, Lee JF, Thung KH, Lai PB, Lau WY. Laparoscopic-assisted resection of right-sided colonic carcinoma: a case-control study. J. Surg. Oncol. 1999; 71: 97-100.

40. Poulin EC, Mamazza J, Schlachta CM, Gregoire R, Roy N. Laparoscopic resection does not adversely affect early survival curves in patients undergoing surgery for colorectal adenocarcinoma. Ann. Surg. 1999; 229: 487-92.

41. Curet MJ, Putrakul K, Pitcher DE, Josloff RK, Zucker KA. Laparoscopically assisted colon resection for colon carcinoma: perioperative results and long-term outcome. Surg. Endosc. 2000; 14: 1062-6.

42. Champault GG, Barrat C, Raselli R, Elizalde A, Catheline JM. Laparoscopic versus open surgery for colorectal carcinoma: a prospective clinical trial involving 157 cases with mean follow-up of 5 years. Surg. Laparosc. Endosc. Percutan. Tech. 2002; 12: 88-95.

43. Kockerling F, Rose J, Schneider C et al. Laparoscopic colorectal anastomosis: risk of post-operative leakage: results of a multicenter study. Laparoscopic Colorectal Study Group (LCSSG). Surg. Endosc. 1999; 13: 639-44.

44. Kockerling F, Reymond MA, Schneider C et al. Prospective multicenter study of the quality of oncologic resections in 
patients undergoing laparoscopic colorectal surgery for cancer. Dis. Colon Rectum 1998; 41: 963-70.

45. Santoro E, Carlini M, Carboni F, Feroce A. Colorectal carcinoma: laparoscopic versus traditional open surgery. A clinical trial. Hepatogastroenterology 1999; 46: 900-4.

46. Karim H, Chafik K, Karim K et al. Risk factors for surgical wound infection in digestive surgery. A retrospective study of 3000 surgical wounds. Tunis Med. 2000; 78: 634-40.

47. Alves A, Panis Y, Pocard M, Regimbeau JM, Valleur P. Management of anastomotic leakage after nondiverted large bowel resection. J. Am. Coll. Surg. 1999; 189: 554-9.

48. Hansen O, Schwenk W, Hucke HP, Stock W. Colorectal stapled anastomoses. Experiences results. Dis. Colon Rectum 1996; 39: 30-6.

49. Regadas FS, Rodrigues LV, Nicodemo AM, Siebra JA, Furtado DC, Regadas SM. Complications in laparoscopic colorectal resection: main types and prevention. Surg. Laparosc. Endosc. 1998; 8: 189-92.

50. Carlson MA, Ludwig KA, Condon RE. Ventral hernia and other complications of 1000 midline incisions. South. Med. J. 1995; 88: $450-3$.
51. Israelson LA. The surgeon as a risk factor for complications of midline incisions. Eur. J. Surg. 1998; 164: 353-9.

52. Tang R, Chen HH, Wang YL et al. Risk factors for surgical site infection after elective resection of the colon and rectum: a single-center prospective study of 2809 consecutive patients. Ann. Surg. 2001; 234: 181-9.

53. Hoemke M, Treckmann J, Schmitz R, Shah S. Complicated divericulitis of the sigmoid: a prospective study concerning primary resection with secure primary anastomosis. Dig. Surg. 1999; 16: 420-4.

54. Marchena Gomez J, Ruiz de la Cuesta E, Gomez Guerra G, Vallejo Gallego I, Garcia-Anguino F, Hernandez Romero JM. Anastomotic stricture with the EEA-Stapler after colorectal anastomosis. Rev. Esp. Enferm. Dig. 1997; 89: 835-42.

55. Sanz-Lopez R, Martinez-Ramos C, Nunez-Pena JR, Ruiz de Gopegui M, Pastor-Sirera L, Tamames-Escobar S. Incisional hernia after laparoscopic vs open cholecystectomy. Surg. Endosc. 1999; 13: 922-4.

56. Regnard JF, Hay JM, Rea S, Fingerhut A, Flamant Y, Maillard JN. Ventral incisional hernias: incidence, date of recurrence, localization and risk factors. Ital. J. Surg. Sci. 1988; 18: 259-65. 